\title{
Roadmap towards Zero Waste Cities
}

\author{
Atiq Uz Zaman* \\ Zero Waste SA Research Centre for Sustainable Design and Behaviour (sd+b), University of South Australia, Australia \\ *Corresponding author: Atiq Uz Zaman, Zero Waste SA Research Centre for Sustainable Design and Behaviour (sd+b), University of South Australia, Australia, Tel: \\ +61 08302 0422; E-mail: atiq.zaman@mymail.unisa.edu.au
}

Received date: February 26, 2014; Accepted date: February 27, 2014; Published date: March 6, 2014

Copyright: $\odot 2014$ Zaman AU. This is an open-access article distributed under the terms of the Creative Commons Attribution License, which permits unrestricted use, distribution, and reproduction in any medium, provided the original author and source are credited.

\section{Editorial}

Currently, the world's cities generate about 1.3 billion tonnes of solid waste per year and the volume is expected to increase to 2.2 billion tonnes by 2025 [1]. Waste generation rates will more than double over the next twenty years in lower income countries. However, this current trend of generating waste is not a recent practice; it comes from the very early stages of modern society. So how would it be possible to transform current cities into zero waste cities?

Zero waste means designing and managing products and processes systematically to avoid and eliminate waste, and to recover all resources from the waste stream [2]. Working towards zero waste has become a worldwide movement that motivates changes in design that make it possible to disassemble and recycle products. To put it simply, zero waste means no unnecessary and unwanted waste from a product at any stage of its life cycle.

The scope of zero waste comprises many concepts that have been developed for sustainable waste management systems, including avoiding, reducing, reusing, redesigning, regenerating, recycling, repairing, remanufacturing, reselling and re-distributing waste resources. Hence, a zero-waste strategy is growing in popularity as best practice. It not only encourages recycling of products but also aims to restructure their design, production and distribution to prevent waste emerging in the first place [3].

In recent years, a number of studies have been conducted to identify the key challenges, drivers, tools and strategies for achieving the zero waste goals [4]. The following sections have been identified as the key steps toward zero waste cities.

\section{Key Steps toward Zero Waste Cities}

\section{Zero waste management}

Traditional concept of waste as something produced at the end of our consumption activities has to be challenged by the new zero waste concept. In the zero waste concepts, waste is considered as a transitional phase of resources which can be taken back to the production process or disposed of to landfill. Hence zero waste management systems include product design, consumption, and resource recovery phases. Zero waste products, based on cradle-tocradle design principles, would eventually not produce any waste during their production stages. At the end of product stage, the life span of the product should easily be extended by repair and thus be ready for reuse again. If not, then the product would easily be dematerialized to reprocess in the creation of a new product. If dematerialization is not possible, then the production process needs to be changed to make it more resource efficient. Finally the non-usable product would be recovered from the household waste stream and diverted from landfill. The zero waste management concepts thus integrate both production of products and management of their endof-life. Therefore, an extended producer and consumer responsibility is very important in zero waste management. Implementing producers' take-back schemes is an effective resource recovery strategy being applied in many countries.

\section{Waste treatment and disposal}

Waste treatment and disposal is another key area on the zero waste roadmap. The technology that we use in waste management systems (such as biological and thermal treatment technology) has affected overall waste management systems overall. Incineration of waste may generate heat and energy but the resources that could potentially be recovered are permanently depleted by the mass burn (incineration) systems. Landfilling waste similarly depletes resources and emits GHG in the atmosphere. Therefore, while thermal treatment and landfill may be temporary waste management solutions, for a permanent and zero waste solution these technologies need to be transformed into zero incineration and no-landfill systems by implementing long term zero depletion principles.

\section{Regulatory strategies}

Regulatory strategies are important for sustainable waste management. Regulatory strategies have long been used to encourage or limit certain mass burn technologies. For instance, laws that restricted disposal of organic, combustible and hazardous waste to landfill imposed higher landfill taxes and provided more incentives would encourage optimum resource recovery.

\section{Governance and infrastructure}

Experts often observe that an effective waste management system reflects good governance. Zero waste governance requires new management approaches and infrastructure. A combination of effective 'hard' and 'soft' infrastructure is required to ensure optimum service to society. Waste collection, storing, sorting and recycling, treatment and disposal facilities are 'hard' infrastructures. Education, regulations and financial systems are 'soft' infrastructures. Community-based waste recycling centres, hazardous waste collection systems and separate waste collection for optimum recycling systems are priority areas for governance and infrastructures. A centralized waste data recording system with time series waste data is very important to analyses, assess and measure the performance of waste management systems. Community recycling centres are identified as priority areas for waste recycling of hazardous, non-hazardous and bulk waste. 
Page 2 of 2

\section{Market creation}

Our current globalized economy is predominantly driven by market systems. Since waste is part of everyday life, market-driven waste management solutions are vital to improve current waste management systems. In a positive market situation, waste management is easier and more cost-effective than in a negative market situation. In most of the developed countries, due to high labour and recovery costs waste is sent to developing countries by accepting the negative consequences of resource and environmental depletions.

\section{Adaptive zero waste strategy and plan}

Any zero waste strategy should be adaptive and flexible to implement. Therefore, rather than very firm and short term policies; zero waste requires flexible and long term waste management strategies. The long term vision may be subdivided into short term targets and milestones. Current globalization systems are unpredictable due to diverse socioeconomic, geopolitical and environmental complexities. Local and decentralized waste management systems may be affected by global economic or environmental factors. The volume of waste exported and imported may be affected by local waste strategies. For instance, due to a higher recycling and incineration rate, Sweden is willing to import waste from neighbouring countries. Local waste management strategy can influence national waste management systems and vice versa. Therefore, the zero waste strategy should predict possible future consequences and be adaptive in nature.

\section{Adaptive zero waste strategy and plan}

Any zero waste strategy should be adaptive and flexible to implement. Therefore, rather than very firm and short term policies; zero waste requires flexible and long term waste management strategies. The long term vision may be subdivided into short term targets and milestones. Current globalization systems are unpredictable due to diverse socioeconomic, geopolitical and environmental complexities. Local and decentralized waste management systems may be affected by global economic or environmental factors. The volume of waste exported and imported may be affected by local waste strategies. For instance, due to a higher recycling and incineration rate, Sweden is willing to import waste from neighboring countries. Local waste management strategy can influence national waste management systems and vice versa. Therefore, the zero waste strategy should predict possible future consequences and be adaptive in nature.

\section{References}

1. Hoornweg D, Bhada-Tata P (2012) What a Waste: A Global Review of Solid Waste Management.

2. ZWIA (2004) Zero Waste Definition Adopted by Zero Waste Planning Group.

3. United Nations Economic Commission for Europe (UNECE) (2011) Climate Neutral Cities: How to Make Cities Less Energy and Carbon Intensive and More Resilient to Climatic Challenges.

4. Zaman AU, Lehmann S (2013) The zero waste index: a performance measurement tool for waste management systems in a zero waste city. J Clean Prod 50: 123-132. 